\title{
Governo eletrônico e capital intelectual nas organizações públicas*
}

\author{
Luiz Antonio Joia**
}

SumÁRIo: 1. Introdução; 2. Revisão bibliográfica e hipóteses de pesquisa; 3. Procedimentos metodológicos; 4. Descrição dos projetos G2G; 5. Observações conclusivas e limitações da pesquisa.

Summary: 1. Introduction; 2. Literature review and research hypotheses; 3. methodological procedures; 4. Description of the G2G projects; 5 . Concluding remarks and research limitations.

Palavras-chave: governo eletrônico; capital intelectual; ativos intangíveis; government-to-government.

Key words: electronic government; intellectual capital; intangible assets; government-to-government.

Este artigo mostra a variação de capital intelectual em organizações públicas envolvidas em empreendimentos government-to-government (G2G). Para tanto, um frame heurístico foi desenvolvido a fim de avaliar o impacto de projetos G2G nos componentes do capital intelectual de agências públicas, isto é, em seus capitais humano, organizacional, de relacionamento e de inovação. Aplicando-se esse frame heurístico a 30 empreendimentos G2G no Brasil, ligando o Banco Central com os tribunais de justiça, detectou-se um impacto positivo no capital intelectual das organizações envolvidas nesses empreendimentos. Além disso, verificou-se que tais empreendimentos G2G influenciaram os componentes do capital intelectual de forma homogênea. A partir daí, o frame foi validado por meio de uma elevada e positiva correlação entre a variação do capital intelectual nas organizações públicas e a percepção de valor dos funcionários envolvidos nesses mesmos empreendimentos. Finalmente, adicionalmente às limitações da pesquisa, algumas conclusões são apresentadas a gestores

\footnotetext{
* Artigo recebido em abr. e aceito em out. 2009.

** Doutor em ciências em engenharia de produção pelo Instituto Alberto Luiz Coimbra de PósGraduação e Pesquisa de Engenharia da Universidade Federal do Rio de Janeiro (Coppe/UFRJ). Professor da Escola Brasileira de Administração Pública e de Empresas da Fundação Getulio Vargas (Ebape/FGV). Endereço: Ebape/FGV — Praia de Botafogo, 190, 5 andar - Botafogo - CEP 22253-900, Rio de Janeiro, RJ, Brasil. E-mail: luiz.joia@fgv.br.
} 
públicos, practitioners e acadêmicos, para que seja entendido o potencial de uso da teoria do capital intelectual para avaliação de iniciativas de governo eletrônico.

Electronic government and human capital in public organizations

This article shows the intellectual capital variation in public organizations involved in government-to-government (G2G) enterprises. A heuristic frame was developed to measure the impact of $\mathrm{G} 2 \mathrm{G}$ projects on the intellectual capital components of public agencies, i.e., on their human, organizational, relational and innovative capitals. This heuristic frame was applied to $30 \mathrm{G} 2 \mathrm{G}$ enterprises in Brazil connecting the Central Bank to the courts of justice and revealed a positive impact on the intellectual capital of the organizations involved. Furthermore, these G2G enterprises influenced the intellectual capital components uniformly. Then the frame was validated by means of a high and positive correlation between the intellectual capital in the public organizations and the perception of value by the workers involved in those enterprises. Finally, the article presents the limitations of the research, as well as a few conclusions so that public managers, practitioners and scholars can understand the potential of applying the intellectual capital theory to assess electronic government initiatives.

\section{Introdução}

Desde o início de 1980 um movimento começou a ser fomentado tanto por acadêmicos quanto executivos para o uso da tecnologia da informação (TI) não apenas como uma ferramenta para processar dados mais rapidamente, mas também como uma poderosa arma estratégica. A necessidade de usar TI como um propiciador para reformular velhos processos, ao invés de apenas automatizar práticas existentes foi percebida por esses acadêmicos e executivos (Davenport e Short, 1990; Venkatraman, 1994).

À medida que a internet tornou-se mais acessível, o redesenho de processos na área pública tornou-se uma realidade, levando todos os níveis de governo a uma busca por maior eficiência, eficácia, efetividade e accountability nas relações com seus stakeholders, no que é chamado hoje de governo eletrônico (Lenk e Traunmüller, 2001:63).

Por outro lado, o entendimento do conhecimento como arma estratégica para uma corporação não é recente. Já em 1945, Frederick Hayek (1945) apresentou pesquisa sobre o uso do conhecimento na sociedade. Em 1962, Fritz Machlup, da Universidade de Princeton, produziu um trabalho de oito volumes sobre o título geral: Knowledge: its creation, distribution, and economic significance (citado por Stewart, 1997). No trabalho, baseando-se em dados de 1958, o autor mostrou que $34,5 \%$ do PIB americano deviam ser alocados ao setor de informação. Em 1993, Peter Drucker analisou a nova economia do 
conhecimento e suas consequências (Drucker, 1993). Assim, a importância de ativos intangíveis para uma corporação e mesmo para países e outros tipos de organizações - incluindo as sem fim lucrativo - tem sido crescentemente justificada por acadêmicos, pesquisadores e practitioners (Roos et al., 1997; Sveiby, 1997; Edvinsson e Malone, 1997; Davenport e Prusak, 1998).

Entretanto, um divisor de águas ocorreu em julho de 1994, quando uma reunião ocorreu em Mill Valley para estabelecer como o conhecimento de uma organização poderia ser mensurado. O conhecimento pode ser intangível, mas isso não significa que não possa ser medido. Como se sabe, os mercados fazem isso quando avaliam o valor de mercado de companhias intensivas em conhecimento num patamar bem superior ao seu valor contábil.

Em 1995, a Skandia - maior empresa de seguros e serviços financeiros da Escandinávia - publicou seu Relatório anual de capital intelectual, baseado no framework Navigator (Edvinsson e Malone, 1997). Outras companhias, como Dow Chemical, Canadian Imperial Bank of Commerce, Pasco etc., apenas para citar algumas, também entraram nessa nova era.

Este artigo se baseia na fusão de dois distintos campos de conhecimento: governo eletrônico e o papel estratégico dos ativos intangíveis nas agências públicas. Ele foi elaborado para desenvolver um frame heurístico que fosse capaz de avaliar a variação do capital intelectual em organizações públicas envolvidas em iniciativas government-to-government (G2G). Em outras palavras, este artigo avalia os resultados intangíveis derivados de projetos $\mathrm{G} 2 \mathrm{G}$ na administração pública, o que ainda é considerado uma fronteira do conhecimento na área de governo eletrônico (Sharma, 2004).

O artigo, após esta introdução, apresenta uma revisão bibliográfica associada ao tema da pesquisa, para justificar os marcos teóricos adotados e as hipóteses de pesquisa a serem testadas. A seguir, são apresentados e justificados os procedimentos metodológicos. Posteriormente, os casos estudados são descritos e os dados deles analisados, assim como testadas as hipóteses de pesquisa. Por fim, são apresentadas as observações conclusivas do trabalho e as limitações inerentes à pesquisa.

\section{Revisão bibliográfica e hipóteses de pesquisa}

\section{O ímpeto por detrás da teoria do capital intelectual}

Não há uma definição única para capital intelectual (CI). Kaufmann e Schneider (2004), por exemplo, analisaram várias definições para esse constructo. A 
maioria delas está associada à definição de ativos intangíveis e a recursos associados ao conhecimento, como atestado por Restage (2003:230): "CI pode ser adequadamente visto como a metacapacidade que uma empresa tem para coordenar, orquestrar e aplicar seus recursos associados ao conhecimento, de forma a criar valor segundo sua visão estratégica". Em linha com essa definição, Petty e Guthrie (2000:158) definem CI como "o valor econômico dos ativos intangíveis de uma corporação".

De acordo com Edvinsson e Malone (1997), Roos e colaboradores (1997), Sveiby (1997) e Stewart (1997) o ímpeto para o desenvolvimento de uma teoria do capital intelectual se fundamentou na crescente razão entre o valor de mercado (M) e o valor contábil (B) de uma organização. Alguns autores, como Ordónez de Pablo (2003:63), não apenas concordam com tal, como também suportam que o capital intelectual de uma firma é a diferença entre seus valores de mercado e contábil.

Alguns podem dizer que diferentes políticas de depreciação poderiam influenciar o cálculo do valor contábil (B). É um ponto válido e a razão pela qual Tobin (1969) sugeriu o uso do custo de reposição, definindo $q$ como valor de mercado/custo de reposição de um ativo. O conceito de custo de reposição foi desenvolvido para homogeneizar as diferentes políticas de depreciação usadas por contadores em todo o mundo. Se $q$ é maior do que 1 , o ativo vale mais do que seu custo de reposição, sendo razoável que a companhia procure adquirir mais quantidade do mesmo. Entretanto, recentemente, esse argumento não tem mais sido capaz de explicar o crescente valor de M/B de algumas empresas.

Uma pergunta porém merece ser feita a essa altura: por que empresas devem medir seu capital intelectual? Segundo Andriessen (2004:232233), por seis razões: o que se mede, se gerencia; para melhorar a gestão de recursos intangíveis; para monitorar efeitos derivados de ações; para traduzir a estratégia organizacional em ações; para ponderar possíveis e distintos cursos de ação; para aperfeiçoar o gerenciamento da organização como um todo.

Esses fatos mostram a crescente pressão a qual as organizações estão submetidas para avaliar seu capital intelectual, de forma a melhorar suas práticas gerenciais e atingir melhores resultados.

Em linha com o apresentado, a teoria do capital intelectual permite às firmas melhor compreender seus ativos intangíveis (Restage, 2003:230). Para tal, é mister entender os componentes do capital intelectual de uma organização. 


\section{Taxonomia do capital Intelectual}

Segundo Kaufmann e Schneider (2004:375), várias categorizações para ativos intangíveis vêm sendo apresentadas. Para esses autores, as abordagens propostas por Edvinsson (1997) e Edvinsson e Malone (1997) parecem ter influenciado fortemente outros pesquisadores. Ademais, Bukh e colaboradores (2001) comparando várias taxonomias propostas para o capital intelectual concluíram que as mesmas têm três coisas em comum: conexão com os funcionários; conexão com os processos internos e a estrutura organizacional; conexão com os clientes.

Em linha com essa perspectiva e baseando-se em pesquisas desenvolvidas por Edvinsson e Malone (1997), Roos e colaboradores (1997), Sveiby (1997) e Stewart (1997), propomos uma taxonomia para o capital intelectual de uma organização, a ser adotada neste artigo. A taxonomia proposta é baseada na seguinte equação:

valor de mercado $=$ valor contábil + capital intelectual

A equação mostra que o valor de mercado possui uma porção tangível (valor contábil) adicionada a um componente intangível. Assim, assumindo que o capital intelectual seja maior do que zero $(\mathrm{CI}>0)$, a relação (valor de mercado/valor contábil) é maior do que $1(\mathrm{M} / \mathrm{B}>1)$. Assim, quanto mais intensiva em conhecimento é uma companhia, maior seu valor M/B (Stewart, 1997; Röos et al., 1997).

O valor contábil (também denominado capital financeiro) é então calculado pela fórmula:

$$
\text { valor contábil }=\text { capital monetário }+ \text { capital físico }
$$

E o capital intelectual — conhecido por goodwill pelos contadores - é calculado usando-se a fórmula:

$$
\text { capital intelectual }=\text { capital humano }+ \text { capital estrutural }
$$

O capital humano não pertence à firma, já que é uma consequência da soma das expertises e habilidades dos seus funcionários. O capital estrutural pertence à firma e pode ser negociado (pelo menos, teoricamente), já que representa a ambiência desenvolvida pela firma para gerar e gerenciar seu conhecimento adequadamente. Ele é composto do capital organizacional, que 
representa a estrutura interna da empresa, seus processos, bases de dados, códigos, cultura, estilo gerencial e redes internas (como intranets); o capital de relacionamento, que diz respeito ao valor das ligações da empresa com seus clientes, fornecedores, subcontratados e outros atores; e o capital de inovação, uma consequência direta da cultura da firma e da sua capacidade de criar conhecimento novo a partir do existente. Assim, a fórmula seguinte sumaria o que já foi dito:

capital estrutural = capital organizacional + capital de relacionamento + capital de inovação

Finalmente, a fórmula do capital intelectual pode ser consolidada da seguinte forma:

$$
\begin{gathered}
\text { capital intelectual = capital humano + capital organizacional + capital de relacionamento } \\
+ \text { capital de inovação }
\end{gathered}
$$

Pode-se, portanto, perceber que o capital intelectual (CI) é composto por quatro constructos, $\mathrm{CH}, \mathrm{CO}, \mathrm{CR}$ e $\mathrm{CIn}$ - capitais humano, organizacional, de relacionamento e de inovação, respectivamente - , cada um deles interagindo com os demais (Hussi e Ahonen, 2002).

\section{Capital intelectual na administração pública}

A teoria do capital intelectual tem sido largamente utilizada no setor privado. Infelizmente, nesse mister, o setor público se encontra bem menos desenvolvido. Existem várias razões para tal, como suportado por Cinca e colaboradores (2003:250). De acordo com os autores, diferentemente do setor privado, cuja performance pode ser avaliada por medidas financeiras, órgãos públicos têm objetivos múltiplos de natureza não financeira. Além disso, embora usando insumos produtivos semelhantes - recursos humanos, conhecimento, capital, matéria-prima e instalações —, o setor público aproveita-se principalmente dos dois primeiros recursos, que são ativos intangíveis. Ademais, o principal resultado gerado pelo setor público é serviço e não produto, e serviços não podem ser medidos diretamente. Finalmente, Cinca e colaboradores (2003:251252), assim como Borins (2001:310), apontam a baixa motivação para adoção de novas práticas gerenciais no ambiente público e a pouca margem de manobra a que os gestores públicos estão submetidos, como mais dois grandes 
obstáculos para a implantação de projetos de capital intelectual na administração pública.

Não obstante tais obstáculos, alguns acadêmicos têm desenvolvido pesquisas para aplicar a teoria do capital intelectual na administração pública. Pode-se citar, por exemplo, Sveiby (1997), que aplicou a teoria do capital intelectual no Departamento de Assistência Social de Adelaide, Austrália. Há também Dragonetti e Roos (1998), que analisaram a AusIndustry — agência pública associada ao Departamento de Indústria, Ciência e Turismo da Austrália, assim como Bontis (2004), que desenvolveu um índice nacional de capital intelectual para a Península Arábica.

Entretanto, há uma grande diferença entre o uso da teoria do capital intelectual no ambiente empresarial e no público, ou seja, o modo como os modelos de análise são validados (Ordónez de Pablo, 2003). Frequentemente, o mundo de negócios valida os modelos de mensuração de seus ativos intangíveis correlacionando os resultados advindos desses ativos para uma firma com a sua respectiva razão M/B (valor de mercado/valor contábil) (Sáenz, 2005:375). Como organizações públicas não possuem valor de mercado, uma maneira alternativa deve ser buscada. Na administração pública, a solução desse problema pode ser encontrada no corpo de conhecimento relativo à mensuração de performance (Cinca et al., 2003:254).

Segundo Ballantine e Cunningham (1999), o reconhecimento crescente da necessidade de monitorar múltiplas dimensões da performance tem conduzido ao desenvolvimento de uma literatura substancial associada a isso (por exemplo, Brignall et al., 1992; Fitzgerald et al., 1991). Entre as mais importantes contribuições para tal literatura, pode-se citar Checkland e colaboradores (1990) que conceptualizaram medidas de performance por meio do conceito de sistemas e das medidas necessárias para mantê-los em equilíbrio ao longo do tempo. Suas pesquisas levaram ao reconhecimento de três níveis de performance que, argumentam eles, devem ser usados para monitorar a performance de um sistema (Checkland, 1981):

v efetividade - a coisa certa está sendo feita;

$\checkmark$ eficácia - os objetivos foram alcançados;

$\checkmark$ eficiência - o uso de recursos é mínimo.

Roebeke (1990) concorda com essas ideias, reconhecendo a necessidade de monitorar efetividade, eficácia e eficiência. Para ele, medidas de efetividade são mais importantes do que medidas de eficácia que, por sua vez, são mais importantes do que medidas de eficiência. 
Além disso, em projetos públicos, a accountability deve também ser avaliada. Para Campos (1990), esse conceito pode ser entendido como uma questão de democracia. Accountability tende a seguir os avanços relativos aos valores democráticos, tais como: igualdade, dignidade humana, participação, transparência e responsabilidade.

Assim, essas quatro dimensões - efetividade, eficácia, eficiência e accountability - consolidadas em uma única dimensão poderiam substituir a razão $\mathrm{M} / \mathrm{B}$, de modo a validar os resultados advindos do uso da teoria do capital intelectual para medir a variação de ativos intangíveis no setor público devido a empreendimentos G2G.

\section{Iniciativas government-to-government e ativos intangíveis na área pública}

Já há algum tempo, eficiência, eficácia e efetividade não satisfatórias, a um alto custo, têm sido detectadas em processos tradicionais governamentais entre duas ou mais organizações públicas. Diante dessa realidade, uma questão tem sido posta: se empresas têm descoberto os enormes benefícios que a internet pode gerar a elas, por meio de ligações digitais com seus parceiros, por que as agências públicas não têm usado essa tecnologia e a integração que ela propicia, para se tornarem mais responsivas a um custo menor? Como os orçamentos públicos têm sido cada vez mais contestados em vários países do mundo e a sociedade vem clamando por uma administração pública mais responsável, processos eletrônicos integrados entre órgãos públicos via internet, conhecidos como government-to-government (G2G), podem ser a resposta a essa questão.

$\mathrm{Na}$ área empresarial, quando todas as tarefas e processos de um empreendimento são centralizados em uma única empresa, é mais simples organizar e avaliar os benefícios intangíveis derivados desse empreendimento. O problema é que, atualmente, um conjunto de diferentes atores pode estar envolvido em um mesmo projeto. Assim, uma questão surge: como é possível gerenciar e medir os resultados intangíveis gerados durante um dado empreendimento, de tal modo que esses resultados possam ser usados em outros projetos existentes, assim como gerenciar o acesso a esses resultados visando a sua aplicação em projetos futuros?

Várias pesquisas importantes têm investigado vários aspectos dessa questão, como Powell (1990); Badaracco (1991); Bahrami (1992); Baker (1994); Powell e Smith-Doerr (1994), apenas para citar alguns. 
Embora importantes, tais artigos pouco abordam como criar, colocar em prática, transferir, armazenar e recuperar os resultados intangíveis de um empreendimento envolvendo diferentes companhias, baseadas em diferentes locais, com distintos, mas importantes deveres. Assim, o próximo passo lógico seria pesquisar grupos interorganizacionais fragmentados. Para alcançar isso, é fundamental entender o papel que a tecnologia da informação tem no fortalecimento dos links de conhecimento entre os atores de projetos envolvendo diversos subcontratados, fornecedores e outras firmas. Interessantemente, esse é exatamente o ambiente do governo.

O governo, como uma coleção de agentes públicos, cada um com seu próprio conhecimento e informação, precisa assegurar-se de que essas agências estão ligadas para compartilhar seus ativos intangíveis. É dito que o governo é (ou deveria ser) similar a um metabusinesses - quasi-firmas ou firmas virtuais, criadas via links digitais entre várias companhias, de tal forma que é quase impossível definir precisamente seus contornos (Keen, 1991).

Fountain (2001:76) analisa esse importante assunto em todo um capítulo de seu livro Building the virtual state, onde ela explica as peculiaridades das redes interorganizacionais na administração pública, declarando: "essa habilidade em preservar competição enquanto a cooperação é fomentada, para desenvolver capacidade de geração conjunta de políticas públicas entre as organizações de governo, é um dos desafios por sob iniciativas G2G na adminsitração pública".

Além disso, Lenk e Traunmüller (2001:64) escolheram ver governo eletrônico em geral e G2G em particular sob uma perspectiva de gestão de conhecimento, de modo que os governos, em seus vários níveis, possam criar, gerenciar e tornar disponível o conhecimento gerado e acumulado pelas organizações públicas em suas bases de dados. Em outras palavras, os autores declaram, indiretamente, que existe uma relação entre iniciativas de governo eletrônico e a variação do capital intelectual de uma dada organização pública.

Infelizmente, nada é dito sobre como medir os ativos intangíveis derivados de redes interorganizacionais, como em projetos $\mathrm{G} 2 \mathrm{G}$, mas apenas que essa é uma questão relevante, devendo ser considerada fortemente pelos gestores públicos e formuladores de políticas públicas (Scholl, 2005:7).

\section{Hipóteses de pesquisa}

Baseadas nas ideias apresentadas anteriormente, duas hipóteses de pesquisa podem ser estabelecidas para posterior teste: 
- Ha - projetos G2G entre organizações públicas aumentam seu capital intelectual;

- $\mathrm{Hb}$ - o impacto de projetos G2G é maior no capital de relacionamento das agências públicas envolvidas.

O racional para a primeira hipótese fundamenta-se no fato de que projetos G2G são suportados por sistemas interorganizacionais que podem propiciar colaboração e ser o lócus para a criação de conhecimento nas agências públicas (Haeckel e Nolan, 1993; Powell et al., 1996; Zack e Serino, 2000; Fountain, 2001).

Por outro lado, empreendimentos G2G podem ser vistos como redes horizontais entre organizações públicas. Segundo Nooteboom (1999) e Koivisto e Ahmaniemi (2001), redes horizontais são definidas como arranjos cooperativos entre firmas na mesma área de atuação, como o setor público, por exemplo. Assim, é esperado que um projeto G2G tenha um maior impacto sobre o capital de relacionamento de uma organização, já que seu propósito é ligar duas ou mais agências públicas digitalmente, propiciando um trabalho colaborativo entre elas. Logo, pode-se pressupor que a maior influência de uma iniciativa G2G se dê no capital de relacionamento de uma organização, já que esse capital envolve a ligação de uma firma com seus parceiros, não importando quem sejam. A segunda hipótese, portanto, testa essa ideia.

\section{Procedimentos metodológicos}

A metodologia usada neste artigo baseou-se em ideias e modelos desenvolvidos por Edvinsson e Malone (1997), Roos e colaboradores (1997), NCI's Kellogg School of Business at Northwestern University (citada por Stewart, 1997), Sveiby (1997), Klein (1998) e Winter (1987). Por meio desse último artigo, o conceito de frame heurístico, desenvolvido por Winter S. em seu artigo "Knowledge and competence as strategic Assets", é largamente empregado, de tal forma que o modelo a seguir proposto pode ser classificado como um frame heurístico.

Segundo Winter (1998:172-173):

Um frame heurístico corresponde a um grau de definição de problema que ocupa uma posição intermediária na sequência entre uma lista longa e indiscriminada de coisas que podem importar de um lado, e um modelo teórico de controle bastante elaborado do outro. Dentro de um frame heurístico, há espaço para 
uma ampla gama de formulações mais específicas do problema — mas também existe estrutura suficiente fornecida pelo próprio modelo para guiar e focalizar a discussão. Por outro lado, uma variedade rica de frames heurísticos diferentes pode representar abordagens plausíveis para um problema apresentado.

Com base nessa formulação, a metodologia apresentada é uma entre muitas que ainda podem ser utilizadas em um futuro muito próximo e representa um esforço para superar o efeito de "paralisia por análise" (Ansoff, 1984) extremamente comum quando se lida com coisas intangíveis, levando a discussões intermináveis e não a resultados práticos. Um modelo é bom não por causa do excesso de rigor que aplica a si mesmo, medido pelo número de variáveis levadas em consideração, mas sim pelo fato de modelar e expressar adequadamente a realidade que enfrenta. Complexidade não é necessariamente sinônimo de bons resultados, e é preciso alguma flexibilidade quando se lida com tópicos para os quais é necessária uma boa dose de senso crítico.

Assim, 30 projetos G2G ligando o Banco Central do Brasil com 30 tribunais de justiça localizados em todo o país foram selecionados para análise futura. O Banco Central do Brasil (BC) foi conectado a várias cortes de justiça por meio de sistemas interorganizacionais baseados na web, para que pudesse trabalhar colaborativamente, como será explicado na próxima seção.

Um questionário baseado em escala Likert de cinco pontos, variando de -2 a +2 , foi criado para avaliar a iniciativa G2G. O capital intelectual (CI) foi dividido em seus componentes, segundo a taxonomia já apresentada: capital humano $(\mathrm{CH})$; capital organizacional (CO); capital de relacionamento (CR); e capital de inovação (CIn). Quatro questões foram desenvolvidas para avaliar o impacto dos projetos G2G nos capitais supracitados, como apresentado a seguir.

Q1 (para avaliar a variação no capital humano): após a implantação do projeto G2G, qual sua percepção acerca dos impactos nas habilidades e competências dos funcionários da organização, gerados por esse empreendimento específico?

Q2 (para avaliar a variação no capital organizacional): após a implantação do projeto G2G, qual sua percepção acerca dos impactos nos processos organizacionais, gerados por esse empreendimento específico?

Q3 (para avaliar a variação no capital de relacionamento): após a implantação do projeto G2G, qual sua percepção acerca dos impactos no relacionamento entre a organização e seus principais intervenientes, gerados por esse empreendimento específico?

Q4 (para avaliar a variação no capital de inovação): após a implantação do projeto $\mathrm{G} 2 \mathrm{G}$, qual sua percepção acerca dos impactos na capacidade de inovação da organização, gerados por esse empreendimento específico? 
Os questionários com as quatro perguntas anteriores foram respondidos pelos responsáveis por cada um dos 30 tribunais de justiça ligados ao Banco Central via projeto G2G. Eles podiam afirmar que o projeto G2G tinha piorado grandemente o capital específico (-2); piorado $(-1)$; sido neutro (0); melhorado $(+1)$; melhorado grandemente o capital específico $(+2)$. Depois disso, verificou-se a existência de outliers relativos à variação de cada capital. $\mathrm{O}$ limite de três desvios-padrão em relação à media foi adotado para classificar um valor como outlier (Hair, 1998:65). Se o escore de uma variação de capital fosse descartado, ele seria substituído pela média dos escores remanescentes desse específico capital (imputation), para não prejudicar a linha inteira da matriz de dados (Kline, 1998:75).

A partir daí, para cada projeto G2G, a variação de capital intelectual foi calculada como explicado abaixo (Edvinsson e Malone, 1997:187):

$$
\Delta \mathrm{Cli}=(\Delta \mathrm{CHi}+\Delta \mathrm{COi}+\Delta \mathrm{CRi}+\Delta \mathrm{Clni}) / 4
$$

onde $i$ é número do projeto G2G e $\Delta$ significa a variação de capital.

Posteriormente, as médias e desvios-padrão das variações do capital intelectual, geradas pelos projetos G2G, foram calculadas e um test $\mathrm{t}$ single-tail foi levado a cabo, de modo a verificar se a variação do capital intelectual podia ser suportada como maior do que zero, para testar se houve acréscimo no capital intelectual do conjunto de dados, devido aos projetos G2G (hipótese Ha).

Usando teste Anova, foi também verificado se o impacto dos projetos G2G nos componentes do capital intelectual foi homogêneo, ou se houve uma influência maior no capital de relacionamento (hipótese $\mathrm{Hb}$ ).

Como sugerido por Kannan e Aulbur (2004:393-401), medidas de percepção foram usadas para validar os resultados. Assim, um questionário circulou entre cinco funcionários, de cada tribunal de justiça, que tomaram parte no projeto $\mathrm{G} 2 \mathrm{G}$, para avaliar suas percepções de valor derivadas do impacto do empreendimento G2G na eficiência, eficácia, efetividade e accountability da organização pública. Antes do preenchimento do questionário, o pesquisador teve uma reunião com os respondentes, explicando os objetivos da pesquisa e as medidas de performance adotadas. Um único valor foi, então, escolhido por cada respondente. Uma escala Likert de cinco pontos, variando de -2 a 2 , foi também usada. Como já dito, eles podiam dizer que suas percepções em relação aos indicadores de performance eram agora: muito pior $(-2)$; pior $(-1)$; neutra (0); melhor (1); ou muito melhor (2) do que antes. As médias de todas as percepções foram calculadas e estatisticamente correlacionadas com 
as variações de capital intelectual, para evitar tendenciosidades advindas das respostas dos responsáveis pelos tribunais de justiça.

Todos os empreendimentos G2G analisados estavam em uso regular há mais de um ano. Esse é um ponto importante porque geralmente há uma defasagem de tempo entre o início de um projeto e seu pleno impacto no capital intelectual de uma organização (Sharma, 2004).

O modelo heurístico aplicado é consolidado na figura 1.

Figura 1

Frame heurístico para avaliar a variação do capital intelectual devido a projetos $\mathrm{G} 2 \mathrm{G}$

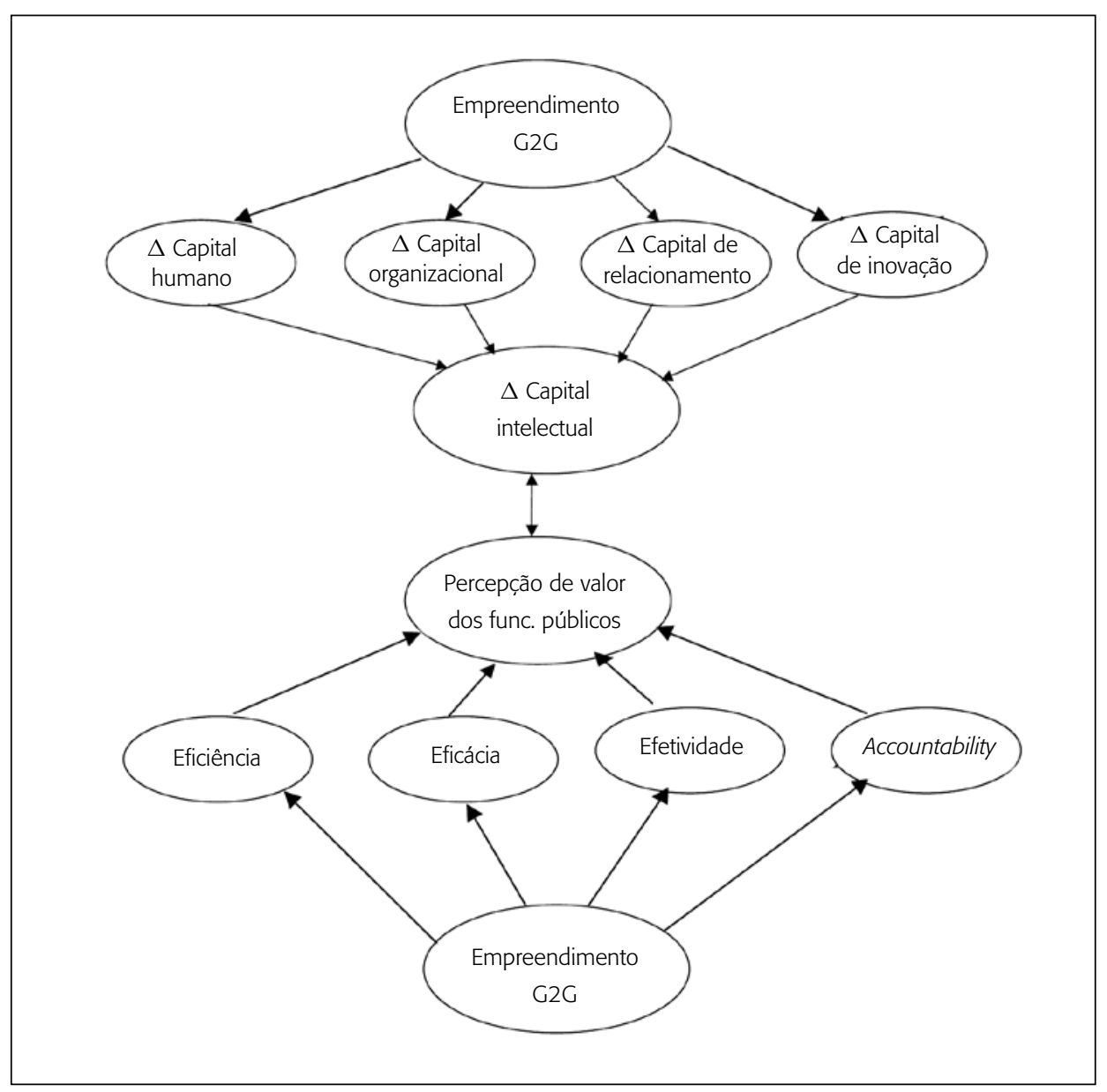




\section{Descrição dos projetos G2G}

\section{O sistema Bacenjud}

A Constituição Brasileira dá a poucas instituições o direito de acesso a contas bancárias tanto de cidadãos quanto de empresas ou, ainda, o poder de confiscar os ativos financeiros de qualquer um deles. Uma dessas instituições é o Tribunal de Justiça que, por meio de ordens judiciais expedidas por seus juízes em todo o território nacional, pode executar essa intervenção, assim como decretar o confisco ou liberação de bens monetários de pessoas ou empresas sob investigação judicial.

Quando os tribunais de justiça expedem ordens relacionadas a informações sobre ativos financeiros tanto de cidadãos quanto de empresas, as mesmas são enviadas diretamente ao Banco Central que, por sua vez, as remete aos específicos destinatários, uma instituição ou o sistema financeiro brasileiro. É quase impossível às cortes de justiça saberem precisamente para quem as ordens devem ser enviadas.

Como já havia um sistema computacional no Banco Central, ligandoo ao sistema financeiro brasileiro (denominado Sisbacen), era relativamente fácil atender às solicitações dos tribunais de justiça. Entretanto, o aumento crescente dessas solicitações expedidas pelos tribunais de justiça obrigou o Banco Central a envolver vários funcionários em tempo integral e a despender consideráveis recursos financeiros apenas para lidar com esses requerimentos. Ao longo dos anos, o número de solicitações cresceu exponencialmente. Nesse meio tempo, a assessoria jurídica do Banco Central alegou que o banco não tinha dever constitucional de atender aos tribunais de justiça nessas demandas específicas. Entretanto, para não prejudicar sua relação com os tribunais de justiça, o Banco Central decidiu repensar seu modus operandi, para continuar assistindo às cortes de justiça. Dessa forma, o banco percebeu a necessidade de inovar seu processo de trabalho, tornando-o mais rápido e responsivo, assim como menos custoso.

\section{O processo inovado}

Em 1999, o Banco Central percebeu a impossibilidade de continuar realizando essa operação manualmente, recebendo mandatos em papel e colocandoos no seu sistema computacional ligado ao sistema financeiro brasileiro. Em 2000, o Banco Central recebia cerca de 300 mandatos por dia, totalizando 
71.775 mandatos apenas nesse ano. Um time de 23 pessoas trabalhando em tempo integral não era suficiente para atender à tal demanda. $\mathrm{O}$ banco estava gastando cerca de US\$ 1 milhão/ano para processar essas requisições, incluídos salários, equipamentos etc.

O banco rapidamente percebeu que havia a necessidade de desenvolver um sistema de informações por meio do qual os próprios tribunais poderiam formular suas requisições que seriam, então, enviadas diretamente por meio digital pelo Banco Central às instituições financeiras.

O banco analisou a possibilidade de revisar o fluxo de informações, aproveitando a existência de acesso à internet na maioria das cortes de justiça. Um sistema baseado na web foi desenvolvido para centralizar a interação entre juízes de 30 tribunais de justiça com o Banco Central, para que eles pudessem preencher as solicitações diretamente. O sistema foi selecionado de modo a que os juízes não precisassem instalar nenhum software específico em seus computadores, reduzindo assim os custos envolvidos nesse processo.

\section{A arquitetura do novo processo interorganizacional}

A partir do momento em que o tribunal assinava um acordo com o Banco Central, esse designava um profissional para gerenciar o futuro sistema. Esse gerente devia conduzir a operação, incluindo e adicionando usuários, alterando dados, mudando senhas, garantindo permissões aos juízes para acessar o sistema e retirando a permissão quando necessário. Essas operações eram feitas pelo próprio sistema, que tinha uma interface dinâmica, de acordo com o perfil do usuário. Os usuários podiam, então, acessar um site restrito na internet e, após terem sua identidade validada, o sistema apresentava templates na web para o preenchimento das requisições judiciais. Esses registros eram gravados diretamente na base de dados corporativa do Banco Central.

Diariamente, às 19 horas, todas as requisições recebidas durante o dia eram processadas e enviadas às instituições financeiras como arquivos eletrônicos. O processo permitia às instituições padronizar suas respostas e enviá-las diretamente ao endereço eletrônico dos juízes.

\section{Benefícios percebidos}

O novo processo trouxe vários benefícios tanto ao Banco Central quanto aos tribunais, o maior deles foi a enorme melhoria de eficiência em processar e 
responder as solicitações. Por meio do sistema antigo, o processamento de uma ordem judicial levava em média cinco dias, a partir do momento em que a mesma era feita e entregue ao sistema financeiro, embora, às vezes, esse prazo pudesse chegar a 20 dias. Esse atraso podia tornar a ordem judicial inútil, já que dava ao suspeito tempo suficiente para remover seus recursos financeiros dos bancos. Com o novo processo, no máximo em 24 horas a ordem era preparada, enviada e respondida pelo sistema financeiro.

A agilidade obtida por meio desse novo processo era fruto não apenas de redução de tempo de ciclo, mas também da oportunidade que as instituições passaram a ter de desenvolver ou comprar software que respondesse automaticamente às ordens, já que os e-mails dos juízes eram fornecidos para as instituições (Judnet, 2001). Outra melhoria no processo derivou da possibilidade de rastreamento nesse novo workflow. Se a ordem não fosse respondida a tempo, o juiz sabia quem deveria ser contatado, podendo realizar um followup e demandar uma resposta imediata.

Em termos financeiros, o novo processo diminuiu os custos tanto para o Banco Central quanto para os tribunais de justiça. Para o banco, os maiores custos eram relacionados aos recursos necessários para completar o processo. Uma ordem pelo processo antigo custava ao banco cerca de $\mathrm{R} \$ 20$ cada, enquanto uma solicitação automatizada custa menos de $\mathrm{R} \$ 1,50$ cada. Os custos para os tribunais foram também reduzidos, já que bastava uma conexão à internet em cada tribunal, eliminando-se custos relacionados com correio e pessoal para lidar com as requisições.

\section{Análise dos dados}

Foram analisados 30 empreendimentos G2G. Os responsáveis pelos tribunais envolvidos nesses projetos foram contatados para preencher um questionário fechado, de modo a relatar a influência dessas iniciativas G2G no capital intelectual dessas respectivas instituições.

Inicialmente, os dados foram analisados e nenhum outlier foi encontrado. Um teste quiquadrado foi aplicado para verificar, com êxito, a normalidade do data set. A assimetria e curtose da amostra foram calculadas, indicando uma distribuição normal de probabilidade. As médias e desvios-padrão da variação dos componentes do capital intelectual e da variação do capital intelectual como um todo dos órgãos públicos envolvidos nos 30 projetos $\mathrm{G} 2 \mathrm{G}$ foram então calculados, como apresentado na tabela 1. 
Tabela 1

Médias e desvios padrão das variações dos capitais

\begin{tabular}{|lccccc|}
\hline & $\begin{array}{c}\text { Capital } \\
\text { humano }\end{array}$ & $\begin{array}{c}\text { Capital } \\
\text { organizacional }\end{array}$ & $\begin{array}{c}\text { Capital de } \\
\text { relacionamento }\end{array}$ & $\begin{array}{c}\text { Capital de } \\
\text { inovação }\end{array}$ & $\begin{array}{c}\text { Capital } \\
\text { intelectual }\end{array}$ \\
\hline Média & 1 & 1,26 & 1 & 1,2 & 1,11 \\
DP & 0,78 & 0,78 & 0,64 & 0,79 & 0,46 \\
\hline
\end{tabular}

Inicialmente, a primeira hipótese foi testada, como apresentado a seguir.

v Ha: projetos G2G entre órgãos públicos aumentam seu capital intelectual.

Ha0 (hipótese nula) - capital intelectual $=0$ (não houve melhoria no capital intelectual das agências públicas em virtude dos projetos G2G).

Ha1 (hipótese alternativa) - capital intelectual $>0$ (houve melhoria no capital intelectual das agências públicas em virtude dos projetos $\mathrm{G} 2 \mathrm{G}$ ).

Usando um teste-t single-tail, concluiu-se que a hipótese nula não podia ser suportada a um nível de significância de 5\% ( $\mathrm{p}=5,43744 \mathrm{E}-14)$.

Assim, a hipótese de que projetos G2G têm impacto positivo no capital intelectual das organizações envolvidas nas iniciativas G2G não pode ser rejeitada.

A segunda hipótese foi então testada.

v Hb: o impacto de projetos G2G é maior no capital de relacionamento das agências públicas envolvidas.

$\mathrm{Hb} 0$ (hipótese nula) $-\Delta \mathrm{CH}=\Delta \mathrm{CR}=\Delta \mathrm{CO}=\Delta \mathrm{CIn}$ (a influência é homogênea em todos os capitais).

$\mathrm{Hb} 1$ (hipótese alternativa) $-\Delta \mathrm{CR}>\Delta \mathrm{CH} ; \Delta \mathrm{CO} ; \Delta \mathrm{CIn}$ (a influência é maior no capital de relacionamento).

Usando teste Anova de igualdade de médias, os seguintes resultados foram obtidos, como apresentado na tabela 2 .

Como $p$-value $=0,4$, a hipótese $\mathrm{Hb} 0$ não pode ser rejeitada a um nível de significância de $5 \%(0,98<2,68)$, um projeto G2G influencia de forma homogênea todos os componentes do capital intelectual. Assim, para amostra colhida, a suposição de que um projeto G2G tivesse maior influência no capital de relacionamento não pode ser suportada. De fato, a influência desses projetos nos capitais humano, organizacional, de relacionamento e de inovação é similar. 
Tabela 2

Teste Anova para a influência dos projetos G2G nos capitais

Anova: fator único - Resumo

\begin{tabular}{|lcccc|}
\hline Grupos & Contagem & Soma & Média & Variância \\
\hline Capital humano & 30 & 30 & 1 & 0,62 \\
Capital organizacional & 30 & 38 & 1,26 & 0,62 \\
Capital externo & 30 & 30 & 1 & 0,41 \\
Capital de inovação & 30 & 36 & 1,20 & 0,65 \\
\hline
\end{tabular}

Anova

\begin{tabular}{|lcrcccc|}
\hline Fonte de variância & SS & df & MS & F & P-value & F crit \\
\hline Entre grupos & 1,7 & 3 & 0,56 & 0,98 & 0,40 & 2,68 \\
Dentro dos grupos & 66,67 & 116 & 0,57 & & & \\
Total & 68,36 & 119 & & & & \\
\hline
\end{tabular}

Finalmente, como forma de validar esses resultados, uma correlação estatística entre as variações do capital intelectual e as variações nas percepções de valor dos funcionários públicos, no que tange ao impacto dos projetos G2G na eficiência, eficácia, efetividade e accountability nas suas organizações, foi calculada (Petty e Guthrie, 2002; Sharma, 2004). O racional é o mesmo de aplicar a razão M/B como um adequado proxy dos ativos intangíveis de uma organização. $\mathrm{O}$ valor de mercado $(\mathrm{M})$ é também um número associado à percepção de valor do acionista em relação à empresa.

A correlação estatística foi de $r=0,74(p=2.9736 \mathrm{E}-06)$, considerada robusta. Assim, segundo a percepção dos empregados dos tribunais de justiça envolvidos nos empreendimentos G2G, essas iniciativas realmente influenciaram as medidas de performance - eficiência, eficácia, efetividade e accountability - das suas organizações positivamente. Como essa é uma correlação forte, pode ser dito que, nesse caso, os resultados e o frame heurístico foram validados.

Para triangular evidências, como sugerido por Yin (1994), visando robustecer a validade da conclusão (Trochim, 2001), a figura 2 foi elaborada para mostrar a relação entre a variação do capital intelectual devido aos projetos $\mathrm{G} 2 \mathrm{G}$, segundo a ótica dos responsáveis pelos tribunais de justiça, e a percepção de valor dos funcionários públicos dos mesmos tribunais envolvidos. 
Figura 2

Avaliação dos projetos G2G pela percepção de valor dos funcionários

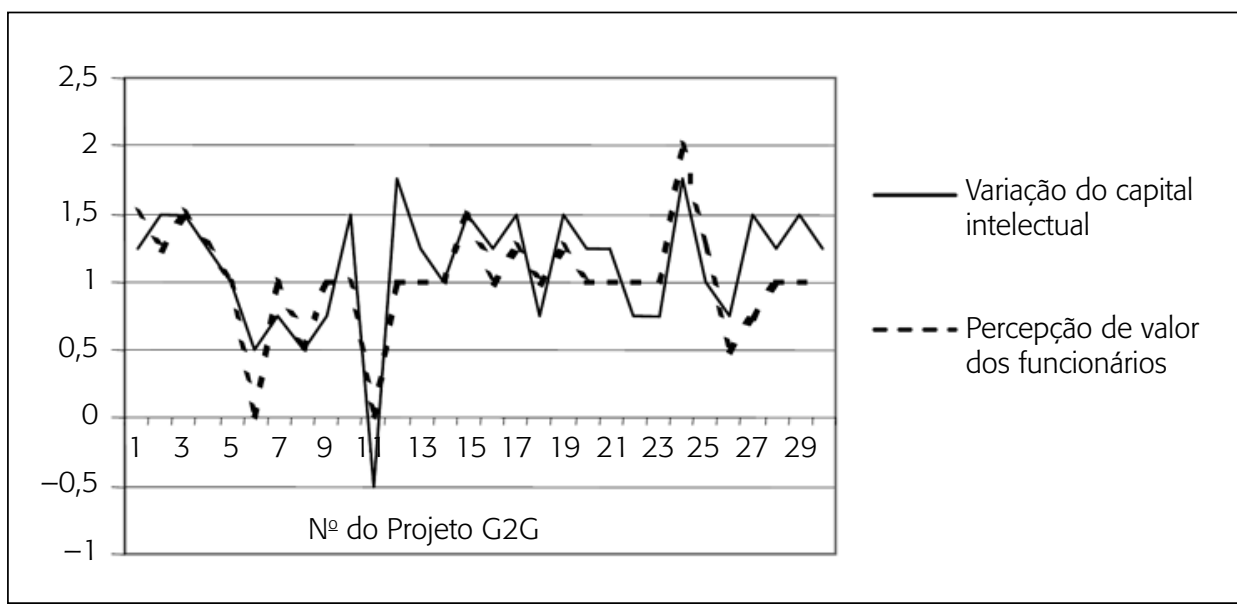

Como pode ser visto na figura 2, não houve dissonância cognitiva entre a percepção de valor dos funcionários dos tribunais de justiça e a dos seus responsáveis.

\section{Observações conclusivas e limitações da pesquisa}

A avaliação de iniciativas de governo eletrônico é ainda um desafio para acadêmicos e gestores públicos (Lau, 2004:239-241), já que a maioria dos benefícios derivados desses empreendimentos é intangível.

Este artigo desenvolveu e testou um frame heurístico baseado na teoria do capital intelectual para avaliar projetos G2G. A partir daí, conclusões interessantes puderam ser obtidas.

Em primeiro lugar, o impacto de projetos G2G de sucesso no capital intelectual de organizações públicas foi positivo, o que está alinhado com as ideias de Sveiby (1997); Dragonetti e Roos (1998); e Bontis (2004).

Em segundo lugar, um projeto G2G de sucesso - além de ligar distintas organizações públicas para que possam trabalhar colaborativamente - tem impacto positivo e homogêneo em todos os componentes do capital intelectual de uma organização pública, seus capitais humano, organizacional, de relacionamento e de inovação. Interessantemente, esses resultados se alinham 
às ideias de alguns pesquisadores que aplicam uma visão sistêmica às redes interorganizacionais (por exemplo, Luhman, 1995; Stahle, 1998; Stahle et al., 2003; Poyhonen e Smedlund, 2004).

\section{Lições aprendidas}

Além do desenvolvimento de um frame heurístico para avaliar o impacto intangível de empreendimentos G2G e baseando-se na análise dos resultados advindos dessa pesquisa, algumas lições aprendidas podem ser apresentadas.

De modo a melhorar o capital humano de agências públicas envolvidas, programas de treinamento em governo eletrônico devem ser levados a cabo, não apenas para os funcionários públicos, mas também para os profissionais de TI, como afirmado por Fountain (2001) e Leitner e Kreuzeder (2005). No caso Bacenjud, por exemplo, sessões específicas de treinamento foram conduzidas para explicar claramente o novo workflow associado ao empreendimento G2G, ouvir o feedback dos usuários e da equipe de TI e aplicar o conhecimento adquirido para melhorar o sistema existente.

Além disso, visando aprimorar o capital organizacional das agências públicas envolvidas nas iniciativas $\mathrm{G} 2 \mathrm{G}$, suas culturas devem ser levadas em consideração antes do projeto G2G ser implantado, como feito no caso Bacenjud. Embora a área pública seja regida pelos mesmos pressupostos legais e procedimentos administrativos, cada órgão público tem sua própria identidade e cultura específica, com seus valores, códigos, símbolos etc. Consequentemente, a análise prévia da cultura organizacional das organizações envolvidas em projetos G2G é de fundamental importância (Leitner e Kreuzeder, 2005). Além disso, o capital organizacional das organizações públicas pode ser incrementado quando iniciativas $\mathrm{G} 2 \mathrm{G}$ propiciam processos inovadores (Lenk e Traunmüller, 2001), como foi o caso das 30 iniciativas investigadas.

Para aumentar o capital de relacionamento das agências públicas envolvidas nos projetos G2G, um ambiente de workgroup deve ser estabelecido, como ocorreu com os tribunais de justiça e o Banco Central, via reuniões conjuntas, objetivando que eles pudessem aprender a trabalhar juntos.

Finalmente, para aumentar o capital de inovação das agências públicas associadas aos empreendimentos G2G, esses têm que estar alinhados às demandas da sociedade, permitindo ao governo se aproximar das práticas em- 
presariais, como atestado por Fountain (2001). O caso Bacenjud atingiu essa meta, criando novas maneiras de lidar com velhos problemas.

Como pôde ser visto, o crescimento do capital intelectual nos tribunais de justiça deveu-se a adequadas ações desenvolvidas pelos stakeholders desses projetos G2G, como é mostrado de forma consolidada na figura 3.

\section{Limitações da pesquisa}

A pesquisa feita apresenta algumas limitações metodológicas que devem ser claramente apresentadas.

Este artigo avaliou a percepção de valor dos funcionários públicos acerca dos resultados oriundos de projetos G2G. Há algumas limitações nessa abordagem, já que eficiência, eficácia, efetividade e accountability não são variáveis que possam ser entendidas sem algum nível de dúvida, mesmo após várias reuniões dos respondentes com o autor. De fato, um certo grau de subjetividade e tendenciosidade por parte dos respondentes pode ter ocorrido (Scandura e Williams, 2000).

A pesquisa também desconsiderou possíveis efeitos cruzados e influências recíprocas das variações de capital intelectual resultantes dos empreendimentos G2G, analisando cada capital separadamente, assim como não considerando as externalidades devidas às iniciativas G2G na sociedade como um todo.

Finalmente, a validade externa deste trabalho (Yin, 1994) é limitada, já que apenas 30 projetos $\mathrm{G} 2 \mathrm{G}$ foram analisados. Assim, não se pode suportar que as mesmas conclusões apresentadas serão válidas para qualquer iniciativa G2G. Por essa razão, uma generalização metodológica, ao invés de estatística (Yin, 1994), foi buscada aqui.

Governo eletrônico é uma área ainda em sua infância. Logo, muito mais pesquisas são necessárias para validar integralmente o frame desenvolvido, assim como para superar as limitações metodológicas apresentadas e criar novos modelos para lidar com as peculiaridades do gerenciamento e mensuração de performance na administração pública.

Por fim, este artigo objetivou explorar as potencialidades derivadas da conexão exploratória da teoria do capital intelectual com projetos de governo eletrônico, visando lançar luz sobre como avaliar o retorno intangível de projetos G2G, considerando que aquilo que se mede, pode ser gerenciado, e que aquilo que se quer gerenciar, precisa ser medido. 
Figura 3

Fatores-chave na variação do capital intelectual de iniciativas G2G

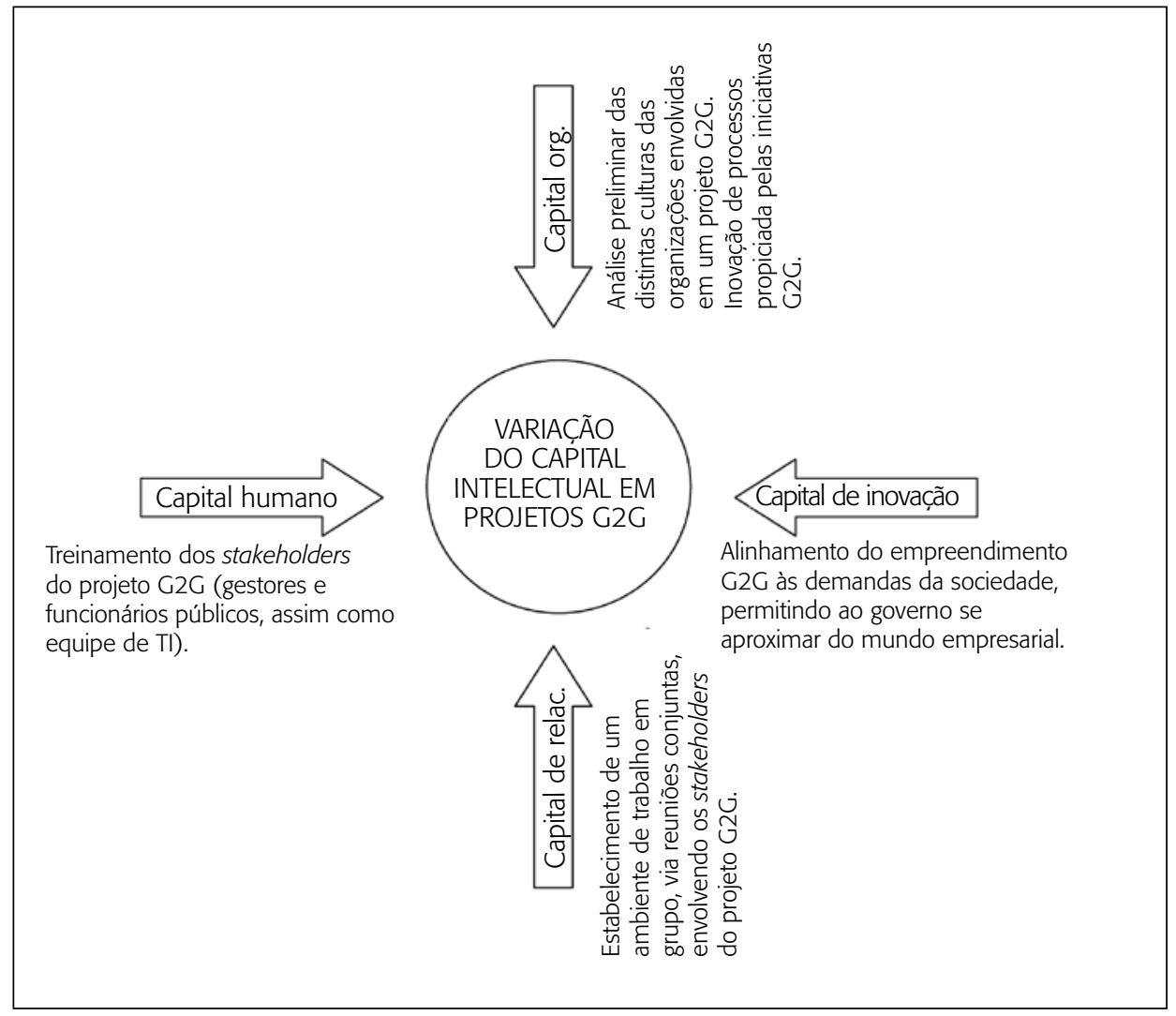

\section{Referências}

ALLE, V. The value evolution: addressing larger implications of an intellectual capital and intangible assets perspectives. Journal of Intellectual Capital, v. 1, n. 1 , p. 17-32, 2000.

ANDRIESSEN. IC Valuation and Measurement: Classifying the State of the Art. v. 5, n. 2, p. 230-242, 2004.

ANSOFF, H. I. Implanting strategic management. Englewood Cliffs: Prentice Hall, 1984.

ARTHUR ANDERSEN \& THE ECONOMIST INTELLIGENCE UNIT. The valuation of intangible assets. Special Report, n. P254, 1992. 
BADARACCO, J. Knowledge links. The knowledge link: how firms compete through strategic alliances. Harvard Business School Press, 1991.

BAHRAMI, $H$. The emerging flexible organization: perspectives from silicon valley. California Management Review, v. 34, n. 4, 1992.

BAKER, W. Building intelligent networks. Networking Smart, chapter 3, McGrawHill, Inc., 1994.

BALLANTINE, J. A.; CUNNINGHAM, N. Analysing performance information needs. In: HEEKS, R. (Ed.). Reinventing government in the information age. Routledge: London, 1999.

BONTIS, N. National intellectual capital index: a United Nations initiative for the Arab region. Journal of Intellectual Capital, v. 5, n. 1, p. 13-39, 2004.

BORINS, S. Encouraging innovation in the public sector. Journal of Intellectual Capital, v. 2, n. 3, p. 310-319, 2001.

BRIGNALL, T. J. et al. Linking performance measures and competitive strategies in service businesses: three case studies. In: DRURY, C. (Ed.). Management accounting handbook. Oxford: Butterworth-Heinemann in conjunction with the Chartered Institute of Management Accountants, 1992.

BUKH, P. N.; LARSEN, H. T.; MOURITSEN, J. Constructing intellectual capital statements. Scandinavian Journal of Management, v. 17, n. 1, p. 87-108, 2001.

CAMPOS, A. M. Accountability: quando poderemos traduzi-la para o português? Revista de Administração Pública, v. 24, n. 2, p. 30-50, 1990.

CHECKLAND, P. B. Systems thinking, systems practice. Chichester: John Wiley, 1981.

; FORBES, P.; MARTIN, S. Techniques in soft systems practice. Part 3: monitoring and control in conceptual models and in evaluation studies. Journal of Applied Systems, n. 17, p. 29-37, 1990.

CINCA, C. S.; MOLINERO, C. M.; QUEIROZ, A. B. The measurement of intangibles assets in public sector using scaling techniques. Journal of Intellectual Capital, v. 4, n. 2, p. 249-275, 2003.

DAVENPORT, T. H.; SHORT, J. E. The new industrial engineering: information technology and business process redesign. Sloan Management Review, p. 11-27, Summer 1990.

; PRUSAK, L. Working knowledge. Harvard Business School Press, 1998. 
DRAGONETTI, N. C.; ROOS, G. La evaluación de ausindustry y el business network program: una perspectiva desde el capital intelectual. Boletín de Estudios Económicos, v. LIII, n. 164, Aug. 1998.

DRUCKER, P. From capitalism to knowledge society. Post-Capitalism Society. HarperCollins Publishers, Inc.,1993.

EDVINSSON, L. Developing intellectual capital at scandia. Long Range Planning, v. 30, n. 3, p. 366-373, 1997.

; MALONE, M. Intellectual capital. HarperBusiness, 1997.

FITZGERALD, L. et al. Performance measurement in service businesses. London: Chartered Institute of Management Accountants, 1991.

FOUNTAIN, J. E. Building the virtual state. Washington, DC: Brookings Institution Press, 2001.

HAIR, J. F. JR. et al. Multivariate data analysis. New Jersey, USA: Prentice Hall, Upper Saddle River, 1998.

HAYEK, F. The use of knowledge in society. The American Economic Review, v. 35, n. 4, Sept. 1945.

HUSSI, T.; AHONEN, G. Managing intangible assets - a question of integration and delicate balance. Journal of Intellectual Capital, v. 3, n. 3, p. 277-286, 2002.

JOHNSON, W. H. A. An integrative taxonomy of intellectual capital: measuring the stock and flow of intellectual capital components in the firm. International Journal of Technology Management, v. 18, n. 5/6/7/8, p. 562-575, 1999.

JUDNET. Troca de informações entre o Poder Judiciário e o Sistema Financeiro Nacional (Sistema Judnet). 2001. Disponível em: <www.ditech.com.br/judnet. htm >. Acesso em: 18 dez. 2005.

KANNAN, G.; AULBUR, W. G. Intellectual capital: measurement effectiveness. Journal of Intellectual Capital, v. 5, n. 3, p. 389-413, 2004.

KAPLAN, R.; NORTON, D. The balance scorecard. Boston, MA: Harvard Business School Press, 1997.

KAUFMANN; SCHNEIDER. Intangibles: a synthesis of current research. Journal of Intellectual Capital, v. 5, n. 3, p. 366-388, 2004.

KEEN, P. Shaping the future. Harvard Business School Press, 1991.

KLEIN, D. The strategic management of intellectual capital: an introduction. In: . (Ed.). The strategic management of intellectual capital. p. 1-7. Butterworth-

Heinemann, 1998. 
KLINE, R. B. Principles and practice of structural equation modeling. New York: The Guilford Press, 1998.

KOIVISTO, T.; AHMANIEMI, R. Verkostoperustainen yrityskäytäntöjen kehittäminen, Helsinki: Edita, 2001.

LAU, E. Principaux enjeux de l'administration electronique dans le pays membres de l'OCDE. Revue Française d'Administration Publique, Ecole Nationale d'Administration, n. 110, p. 225-244, 2004.

LEITNER, C.; KREUZEDER, M. Organizational changes, skills and the role of leadership required by e-government. In: INTERNATIONAL EGOV CONFERENCE. 4., Copenhagen, Denmark, Springer-Verlag, Berlin, Heidelberg, Germany, 2005. Proceedings... 2005. p. 210-217.

LENK, K.; TRAUNMÜLLER, R. Broadening the concept of electronic government. In: PRINS, J. E. J. (Ed.). Designing e-government, Kluwer Law International, 2001. p. 63-74.

LUHMAN, N. Social systems. Stanford, USA: Stanford University Press, 1995.

MARR, B.; GRAY, D.; NEELY, A. Why do firms measure their intellectual capital? Journal of Intellectual Capital, v. 4, n. 4, p. 441-464, 2003.

NOOTEBOOM, B. Inter-firm alliance: analysis and design. London: Routledge, 1999.

ORDÓNEZ DE PABLO, P. Intellectual capital reporting in Spain: a comparative review. Journal of Intellectual Capital, v. 4, n. 1, p. 61-81, 2003.

PETTY, R.; GUTHRIE, J. Intellectual capital literature review - measurement, reporting and management. Journal of Intellectual Capital, v. 1, n. 2, p. 155-176, 2002.

POWELL, W. W. Neither market nor hierarchy: network forms of organization. In: STAW, B. M.; CUMMINGS, L. (Eds.). Research in organizational behavior. Greenwich, London: JAI Press, 1990.

; SMITH-DOERR, L. Networks and economic life. In: SMELSER, N.; SWEDBERG, R. (Eds.). The handbook of economic sociology. Princeton, NJ: Princeton University Press, 1994. p. 368-402.

; KOPUT, K. W. Inter-organizational collaboration and the locus of innovation: networks of learning in biotechnology. Administrative Science Quarterly, v. 41, n. 1, p. 116-145, 1996. 
PÖYHÖNEN, A.; SMEDLUND, A. Assessing intellectual capital creation in regional clusters. Journal of Intellectual Capital, v. 5, n. 3, p. 351-365, 2004.

RESTAGE, P. N. The nature and role of IC - rethinking the process of value creation and sustained enterprise growth. Journal of Intellectual Capital, v. 4, n. 2, p. 227-248, 2003.

ROEBEKE, L. Measuring in organizations. Journal of Applied Systems Analysis, n. 17 , p. 115-122, 1990.

ROOS, J. et al. Intellectual capital. Macmillan Business, 1997.

SÁENZ, J. Human capital indicators, business performance and market-to-book ratio. Journal of Intellectual Capital, v. 6, n. 3, p. 374-384, 2005.

SCANDURA, T. A.; WILLIAMS, E. A. Research methodology in management: current practices, trends, and implications for future research. Academy of Management Journal, v. 43, n. 6, p. 1248-1264, 2000.

SCHOLL, H. J. Organizational transformation through e-government: myth or reality? In: INTERNATIONAL EGOV CONFERENCE. 4., Copenhagen, Denmark, Springer-Verlag, Berlin, Heidelberg, Germany, 2005. Proceedings... 2005. p. 1-11.

SHARMA, S. K. Assessing e-government implementations. Electronic Government: An International Journal, v. 1, n. 2, p. 198-212, 2004.

STAHLE, P. Supporting a system's capacity for self-renewal. Helsinki: Yliopistopaino, 1998.

; STAHLE, S.; PÖYHÖNEN. Analyzing dynamic intellectual capital: systembased theory and application. Lappeenranta: Lappeenranta University of Technology, 2003.

STEWART, T. A. Intellectual capital. Doubleday/Currency, 1997.

SVEIBY, K. E. The new organizational wealth. Berret-Koehler Publishers, Inc., 1997.

TOBIN, J. A general equilibrium approach to monetary theory. Journal of Money, Credit and Banking, v. I, p. 15-29, 1969.

TROCHIN, W. M. K. The research methods knowledge base. 2. ed. Disponível em: <www.trochim.human.cornell.edu/kb/index.htm>. Acesso em: March 2001.

VENKATRAMAN, N. IT - enable business transformation: from automation to business scope redefinition. Sloan Management Review, Cambridge, v. 35, n. 2, p. 73-87, Winter 1994. 
WINTER, S. Knowledge and competence as strategic assets. In: KLEIN, D. (Ed.). The strategic management of intellectual capital. Butterworth-Heinemann, 1998. p. 165-187.

YIN, R. Case study research: design and methods. 2. ed. Thousand Oaks, California: Sage Publications, 1994.

ZACK, M. H.; SERINO, M. Knowledge management and collaboration Technologies. In: SMITH, D. E. (Ed.). Knowledge, groupware and the internet. ButterworthHeinemann, 2000. 